\title{
Los proyectos editoriales de Mario Verdaguer: la revista Mundo Ibérico y las editoriales Lux y Apolo
}

\author{
Mario Verdaguer's publishing projects: the Mundo \\ Ibérico magazine and Lux and Apolo publishing houses
}

\author{
Diana Sanz Roig \\ Investigadora "Juan de la Cierva" \\ Universitat Pompeu Fabra-TRILCAT
}

\section{RESUMEN}

Este trabajo se propone analizar los proyectos editoriales de Mario Verdaguer - novelista de vanguardia, crítico, traductor, pintor y ocasional escritor de poesía y teatro- que trató de mantener un no siempre fácil equilibrio entre el arte y los negocios. A la búsqueda de un beneficio económico que convertía el comercio de bienes culturales en un comercio como cualquier otro, Verdaguer se propuso conjugar la nueva literatura y la literatura comercial, como se pone de manifiesto en la voluntad integradora de la revista Mundo Ibérico, y en las apuestas literarias de las editoriales Lux y Apolo, que sacaron a la luz experimentos vanguardistas, traducciones de encumbrados escritores europeos, y, al mismo tiempo, libros de viajes o novelas para señoritas. A través de su correspondencia inédita, el presente artículo incidirá en su tarea de editor, traductor y director literario y en el papel de mediador que Verdaguer desempeñó entre la modernidad y el academicismo.

Palabras Clave: Mario Verdaguer, Mundo Ibérico, Lux, Apolo, campo editorial, periodismo literario, entreguerras.

\begin{abstract}
This paper aims to analyze Mario Verdaguer's publishing projects. Avant-garde novelist, critic, translator, painter and occasional poet and dramatist, Verdaguer kept a difficult balance between art and business. Searching an economical profit which turned the cultural goods trade into a trade like any other one, Verdaguer aimed to combine the new literature and the commercial, as shown by Mundo Ibérico's conciliator will, and Lux's and Apolo's aesthetic bets. These publishing houses gave birth to avant-garde experiments, translations from well-known European authors, and, at the same time, travel books and novels for young ladies. Through his unpublished collected letters, this paper will go in depth into his publishing and translating activities and into his role as mediator between modernity and academism.
\end{abstract}

Key words: Mario Verdaguer, Mundo Ibérico, Lux, Apolo, publishing field, literary journalism, interwar period. 


\section{PRELIMINARES ${ }^{1}$}

La figura de Mario Verdaguer (Menorca 1885-Barcelona 1973), novelista, crítico, traductor, pintor y eventual escritor de poesía y teatro, nos permite acercarnos al estudio de aquellos individuos que, si bien tímidamente, introducen ciertas fisuras con respecto a las normas formales, estéticas o ideológicas de la cultura y la política de su tiempo. En efecto, si en su tarea como crítico -desarrollada sobre todo en diarios como La Vanguardia ${ }^{2}$ o en revistas como Mundo Ibérico (1927) o Europa (1933) — apenas observamos una revolución formal o estética, y abundan temas trasnochados y autores más cercanos al academicismo, más arriesgadas son sus tentativas como dramaturgo -El sonido $13(1930)^{3}$, o la inédita Espejo curvo-, o sus exploraciones como narrador. En este género, se distinguen por su modernidad El marido, la mujer y la sombra (1927), La mujer de los cuatro fantasmas (1931) o El intelectual y su carcoma (1934), piezas reseñables en su época pero todas ellas hoy olvidadas y con escaso atractivo para el lector actual.

Esta actitud ecléctica, que Verdaguer demostró como escritor ${ }^{4}$, la trasladó también a su tarea de editor y director literario, actividades en las que se propuso conjugar la nueva literatura y la literatura comercial. Muy sucintamente, y desde la perspectiva de la difusión y de la circulación de libros, la teoría de campo de Pierre Bourdieu, aplicada al mundo editorial (1977 y 1999), puso de manifiesto la estructura desigual del mercado, organizada sobre dos polos: el de la gran producción, comercial y de consumo, que se rige por las leyes del mercado, y el de la producción minoritaria, estimulada por principios intelectuales o estéticos. Esta oposición, que se halla por doquier, es el principio generador de gran parte de los juicios que en materia de teatro, cine, arte o literatura, quisieron establecer la frontera entre lo que es arte, y lo que no lo es. Es decir, la diferencia entre el arte burgués y el arte intelectual, entre el arte tradicional y el arte de vanguardia. Sin teorizar ni aplicar a su modelo editorial etiquetas o terminologías concretas, pero consciente de la liberalización que experimentaba el mercado de su época, Verdaguer supo mantenerse entre ambos polos, a la búsqueda de un beneficio económico que convertía el comercio de bienes culturales en un comercio como cualquier otro. Y es que, en efecto, en la tarea de editor convergen a la vez el arte y los negocios, matrimonio a menudo imposible que se ha repetido a lo largo del tiempo. A

\footnotetext{
${ }^{1}$ Agradezco a Domingo Ródenas y al comité de evaluación de Revista de Literatura su lectura atenta y comentarios.

${ }^{2}$ Cf. Diana Sanz Roig (2010).

${ }^{3}$ El sonido 13 se estrenó en el Teatro Fantasio el 19 de febrero de 1930 gracias a Rafael Martínez Romarate.

${ }^{4}$ Cf. Fuentes Mollá (1985: 32).
} 
este respecto, Verdaguer practicó como editor un papel de mediador entre la nueva literatura y la literatura comercial que será visible sobre todo en su tarea de traductor y director literario.

Agente activo en el mercado de la traducción (Verdaguer se había iniciado en la tarea a través de los partes de guerra), recordada todavía es su versión de La montaña mágica de Thomas Mann o sus traducciones de Prosper Mérimée, Ernst Jünger, Giovanni Papini, Panaït Istrati o Stefan Zweig. ${ }^{5}$ En este sentido, el escritor menorquín favoreció la transferencia cultural, que como precisa Michel Espagne (2009: 201) se define como la orientación metodológica que ilustra las imbricaciones y los mestizajes entre espacios nacionales o espacios culturales de manera general. Con este marco teórico de fondo, y tomando también en consideración la sociología de la traducción desarrollada en el Centre de Sociologie Européenne de París, este trabajo pretende examinar la colaboración de Verdaguer en dos editoriales — Lux y Apolo- como autor, traductor y director literario- y su participación en una revista —Mundo Ibérico (1927)— como director y crítico.

\section{LA REVISTA MUNDO IBÉRICO (1927)}

Mundo Ibérico, subtitulada Revista quincenal ilustrada, fue creada en 1927 por Mario Verdaguer, Juan Balagué, propietario de la editorial Lux y de la Librería Central, y el poeta Enrique de Leguina. Como indica su propio título, la revista puso de manifiesto una voluntad integradora y un acercamiento a culturas de distinto signo, voluntad que compartía con La Gaceta Literaria, también creada en 1927, si bien se distinguía de la misma en sus índices de calidad, notablemente inferiores en el caso de la primera ${ }^{6}$. El primer número de la revista aparecía en Barcelona el 5 de junio de 1927; el último, el 1 de noviembre del mismo año, después de una serie de diez entregas, todas ellas de periodicidad quincenal, con excepción de la última, que salía a la luz al

${ }^{5}$ Cf. Véase la entrada que Domingo Ródenas dedica a su faceta de traductor en el Diccionario Histórico de la Traducción en España (2009: 1141-1142).

${ }^{6}$ La impresión que tenía Verdaguer sobre la calidad de la revista parece sin embargo muy distinta. En carta a su hermano Joaquín del 6 de agosto de 1927, Verdaguer le aconseja sobre la conveniencia de privilegiar su colaboración en Mundo Ibérico frente a su participación en la revista Mediterráneo: «No veo inconveniente alguno en que colabores en Mediterráneo y en Mundo Ibérico a la vez, pues no has concedido a nadie la exclusiva de tus artículos. Yo mismo he aceptado el colaborar en La Esfera y Nuevo Mundo. (...) Creo te conviene dar a Mundo Ibérico la preferencia en cuestión de calidad, pues nuestra revista es considerada por la plana mayor de la literatura española como algo serio, y Mediterráneo, en estas esferas, está complemente desprestigiada». Cf. Correspondència rebuda per Mario Verdaguer [a partir de ahora CMV], Cartes a la seva família (1903-1962), "Cartes al seu germà Joaquim» (44-117), 30 de septiembre de 1927, Ms. 3138, n. ${ }^{\circ}$ 80. Barcelona: Biblioteca de Catalunya. 
cabo de un mes, el 1 de diciembre de 1927. Publicada por la editorial Lux, la redacción de Mundo Ibérico se ubicaba en el mismo local, en la calle Consejo de Ciento número 347 de la ciudad condal, y se vendía por suscripción, a 10 pesetas para los lectores de España, Portugal y América; 15, para el público de otros países, y 50 céntimos el número suelto. La revista, que se financiaba con la publicidad de anuncios tan diversos de compañías navieras, automovilísticas, academias de idiomas, balnearios, revistas de moda, desinfectantes, vinos, neumáticos, empresas de material hospitalario o escuelas de comercio, contaba con Leguina como secretario y Mario Verdaguer como director. Con ocasión de la Fiesta del Libro y de la Raza, y de la Exposición Hotelera en Barcelona, Mundo Ibérico publicó dos números extraordinarios los días 12 y 30 de octubre de 1927. En una carta a su hermano Joaquín, Verdaguer reconoce el sustancioso volumen de anuncios que han alcanzado para éste último: «tenemos ya más de veinte mil pesetas de anuncios y como va creo que llegaremos a las cuarenta mil» ${ }^{7}$. Al esfuerzo invertido en la revista se referirá el escritor menorquín en una carta a su familia del 19 de julio de 1927:

Yo estoy muy atareado con mis cosas y especialmente con la Revista, que me trae mucho trabajo (...) La Revista tiene éxito y me parece que de continuarse así conseguiremos que arraigue. Allá veremos. No será porque no ponga en ella todo mi esfuerzo ${ }^{8}$.

La aparición de Mundo Ibérico debe ligarse, necesariamente, al interés temprano de Verdaguer por el mundo editorial y el universo de las revistas. De hecho, en la introducción a Un intelectual y su carcoma, reeditada por Planeta en la colección Las mejores novelas contemporáneas, el escritor menorquín reconoce que en sus años de bachillerato ya había expuesto a sus compañeros su propósito de publicar una revista9. Este proyecto, según López Antuñano (1992: 4), se concretaría en la efímera Alma Lírica. No obstante, el deseo de dirigir una revista ambiciosa tomará forma en la conocida tertulia del Ateneíllo de Hospitalet, reunión que dirigió el pintor uruguayo Rafael Barradas en su casa de la calle Porvenir, en la entonces periferia barcelonesa. Entre los habituales, el poeta Juan Gutiérrez Gili; el periodista Luis Góngora; los críticos Guillermo Díaz-Plaja, Lluís Montanyà, Sebastià Gasch o José María Sucre; el artista Ángel Ferrant; el librero Juan Balagué, y Mario Verdaguer, como acreditan algunas cartas del pintor conservadas en su epistolario $^{10}$. Entre los transeúntes, Federico García Lorca, Salvador Dalí,

${ }^{7}$ Cf. CMV , Cartes a la seva família (1903-1962), «Cartes al seu germà Joaquim» (44117), 30 de septiembre de 1927, Ms. 3138 , n. ${ }^{\circ}$ 80. Barcelona: Biblioteca de Catalunya.

${ }^{8}$ Cf. $C M V$, «Cartes als seus pares i a la seva germana Teresa» (1-43), 19 de julio de 1927, Ms. 3138, n. ${ }^{\circ}$ 41. Barcelona: Biblioteca de Catalunya.

${ }^{9}$ Cf. Mario Verdaguer (1974: 1228).

${ }^{10}$ Cf. $C M V$, «Cartas de Rafael Barradas», Ms. 3139-I (A-CA), n. ${ }^{\circ} 141-144$. Barcelona: Biblioteca de Catalunya. Ante la noticia de su muerte, Verdaguer le dedica un obituario en 
Ramón Gómez de la Serna, Marinetti, Catalina Bárcena o Gregorio Martínez Sierra $^{11}$, que como Verdaguer percibieron en Barcelona un clima apropiado para descubrir a los escritores y críticos que se postulaban en favor de la modernidad. En esta ciudad, Verdaguer entró en contacto con las redacciones nocturnas de la prensa catalana; las tertulias del Lion d'Or, El Gato Negro, Casa Juan, Restaurant Carbó o La Puñalada; reuniones de sociedad como el salón de la Condesa de Castellà (consorte de Salvador Armet, director de la sección extranjera de El Día Gráfico), la reunión del editor Juan Balagué, o la del Ateneíllo de Hospitalet, que Barradas impulsó en su casa por motivos de salud. Una fotografía de esta tertulia aparece en el último número de Mundo Ibérico, mal presagio, quizá, de su temprana desaparición.

En este sentido, la revista ejemplifica bien el fracaso de una aventura económica que no supo equilibrar los aspectos mercantiles de la empresa y los principios estéticos que le hubieran otorgado mayor capital simbólico. Poco hábil en el dominio de las leyes de funcionamiento del campo de producción y de la circulación de bienes culturales, Mundo Ibérico quiso, como señala Jordi Gracia (2000: 25), insertarse en un espacio para el que todavía no existía un público. Incapaz de combinar con éxito la producción de vanguardia y la producción comercial, la revista fracasará en su intento de privilegiar por igual la producción y el campo de los productores, y la difusión, el público y las tiradas, o la inmediatez y temporalidad de los best sellers que promocionaba. A este respecto, y pese a su estética vanguardista, lejana sin embargo de la radicalidad de otras publicaciones, la revista nunca incurrió en la provocación, la extravagancia o el exhibicionismo, y acogió en pie de igualdad la actividad creadora de tres generaciones, la del 98, 14 y 27. Así lo manifiesta la atención y colaboración de escritores tan dispares como José María Salaverría, Eduardo Gómez de Baquero, Rafael Cansinos Assens, Ramón Gómez de la Serna, Melchor Fernández Almagro, Benjamín Jarnés o Ernesto Giménez Caballero.

A esta nómina de escritores, deben sumarse una serie de autores, hoy prácticamente olvidados, que cultivaban una especie de periodismo cultural, de

el diario La Vanguardia: «Un artista desaparecido. Rafael Barradas», 15 de febrero de 1929, 5 y 6. El crítico Guillermo Díaz-Plaja (1966: 60) recordaría, años más tarde, el homenaje que le rindieron sus amigos catalanes en Barcelona: «Un grupo de sus amigos fuimos al puerto y arrojamos al mar -en una impresionante y sobria ceremonia- una corona de flores en su memoria y homenaje».

${ }^{11}$ Sebastià Gasch, vanguardista por excelencia, recuerda las personalidades que se congregaban en el Ateneíllo: «En los años veinte íbamos todos los domingos al Ateneíllo José María Sucre, Sánchez-Juan, Gutiérrez Gili, Leguina, Juan Alsamora, Luis Góngora, DíazPlaja, el crítico literario Luis Montanyà, Salvador Dalí, García Lorca, el dibujante Manuel Font, Mario Verdaguer, novelista de extraordinario éxito, y quien esto escribe». Vid. Gasch (1971: 142). Véanse también las estampas sobre el Ateneíllo que incluye Verdaguer (1957: 295-304) en su libro de memorias Medio siglo de vida íntima barcelonesa. 
escasa calidad. Compañeros de Verdaguer en La Vanguardia, Valerio Serra y Boldú, Lafuente Vanrell, Santiago Vinardell o el poeta Juan Gutiérrez Gili participarán también en la aventura de Mundo Ibérico. De la prensa de Madrid, Verdaguer conseguirá para su publicación las colaboraciones de Augusto Martínez Olmedilla, Cristóbal de Castro, Estévez-Ortega, José Francés, Antonio Ballesteros de Martos o Ángel Dotor. Bajo el pseudónimo de Felipe Centeno, también María Luz Morales colaborará en la revista, distinguiéndose sin embargo del resto de sus compañeros.

No obstante, como señala Gracia (2000: 24), es probable que ni los unos ni los otros, tuvieran noticia muy clara de lo que significaba el proyecto de Mundo Ibérico, revista que se propuso hacerse un hueco en un espacio que pretendía ser a la vez comercial e intelectual. Prueba de ello es el texto publicado en el primer número de la revista, que explica con claridad su programa de intenciones y el público al que va destinado:

\begin{abstract}
El periodismo moderno ha ido evolucionando y al desprenderse, lenta pero seguramente, de las comuniones políticas para convertirse en empresas industriales que solo aspiran a recoger día por día los latidos de la opinión pública, ha tomado un singular carácter ecléctico y al lado de las grandes firmas literarias y la luminosa siembra ideológica de las más altas voces del pensamiento nacional, figuran ampliamente aquellos temas (deportes, cine, etc.) que apasionan e interesan vivamente a las multitudes, sin distinción de clases sociales ${ }^{12}$.
\end{abstract}

Pese a este nuevo horizonte, Mundo Ibérico fracasó en su intento de conciliar una cultura de minorías y una oferta dirigida a un público más amplio. Mundo Ibérico quiso ser una plataforma de influencia, un lugar donde proyectar los anhelos literarios y el compromiso ético de su director, y una representación de la actividad científica de la crítica. En efecto, las relaciones que Verdaguer establecería a través de la revista le granjearon buena fama y le permitieron aspirar a un liderazgo intelectual que, equivocadamente, Gómez de la Serna vaticinaba para él. El propósito de convertir a la revista en una plataforma de influencia se pone de manifiesto en una carta de Verdaguer a su hermano del 8 de febrero de 1927, que lleva el membrete de Lux y Mundo Ibérico: «será una revista de gran altura y en ella colaborarán las mejores firmas de España, Portugal y América Latina ${ }^{13}$. No obstante, este objetivo se consiguió a medias ya que como hemos mencionado Verdaguer se rodeará de una nómina de colaboradores muy dispar. Motivos comerciales o de tipo personal (no debemos ignorar el interés de Verdaguer por congraciarse con los escritores y periodistas que podían reseñar sus novelas en los diarios de Madrid) explican esta heterogeneidad. Una novela como El marido, la mujer y

\footnotetext{
12 Anónimo (Mario Verdaguer con toda probabilidad), «Al comenzar», Mundo Ibérico, 5 de junio de 1927, n. $^{\circ} 1,3$.

${ }^{13}$ Cf. CMV, Cartes a la seva família (1903-1962), «Cartes al seu germà Joaquim» (44117), 8 de febrero de 1927, Ms. 3138. Barcelona: Biblioteca de Catalunya.
} 
la sombra (1927) fue reseñada, como indica Ródenas (2009: 433), por Cansinos Assens en La Libertad, Ballesteros de Martos en El Sol, Andrenio en La Voz, Lafuente Vanrell y José Ma Salaverría en La Vanguardia, Giménez Caballero en La Gaceta Literaria y Benjamín Jarnés en Revista de Occidente. Todos ellos fueron colaboradores de Mundo Ibérico.

La revista proyectará el gusto literario de Verdaguer que, como en el caso de su obra de creación, se acercará al impresionismo mironiano y a la experimentación de la vanguardia ${ }^{14}$. En este sentido, nuevos prosistas como Jarnés comparten espacio con representantes de la prosa novecentista como José Francés, al mismo tiempo que se trata de conciliar la crítica realista y la crítica que defendía las novelas de vanguardia. Enfrentado como autor a los problemas de su oficio y a su papel como intelectual ${ }^{15}$, Verdaguer tratará de asumir en Mundo Ibérico - y en sus proyectos editoriales en general- un compromiso ético, difícil y no siempre posible, que pretenderá renovar el periodismo español, acercando el autor al público y modernizando la literatura y la vida literaria española ${ }^{16}$.

Mundo Ibérico será también una representación de la actividad científica de la crítica, y contribuirá al proceso de su incipiente profesionalización ${ }^{17}$. En este sentido, sabemos por el epistolario de Verdaguer que la revista no aceptaba ninguna colaboración gratuita y proponía a sus críticos una remuneración de 25 pesetas por cada artículo ${ }^{18}$. Apoyado en la autoridad y el crédito que había alcanzado por esas fechas, Benjamín Jarnés solicita a Verdaguer la suma de 50 pesetas y un artículo mensual, que resultará al final en una única colaboración:

Mi felicitación por su Mundo Ibérico. Respecto a mi colaboración, esto: vivo de un pequeño sueldo del Estado y de las (...) cantidades que puede proporcionarme la Revista de Occidente y pocas publicaciones más (...). Mi deseo es contar con tres o cuatro cantidades fijas, mensuales, que me permitan comenzar a escribir más libros —novela, especialmente, porque hasta hoy me he pasado el tiempo afinan-

${ }^{14}$ Cansinos Assens, en el último tomo de La nueva literatura (1927), le dedica un capítulo que discurre en torno a la literatura que han inspirado las Islas Baleares y el cambio que representa El marido, la mujer y la sombra con respecto a su novela anterior, La isla de oro. Para Cansinos Assens (1927: 471), «tal transición no se ha operado bruscamente sino que le ha bastado ahondar en los misterios del psicoanálisis y volar los bastidores realistas de su taller novelesco».

${ }^{15}$ Al hilo de El marido, la mujer y la sombra y El intelectual y su carcoma, Domingo Ródenas (2009: 431-491) ha reflexionado sobre la posición del artista entre la obra y la sociedad. Véanse en particular las pp. 455 y ss.

${ }^{16}$ Este deseo comulga también con la ambición de Giménez Caballero y Guillermo de Torre en La Gaceta Literaria. Cf. Anónimo, «La información literaria en los periódicos», La Gaceta Literaria, n. ${ }^{\circ}$ 6, 15 de marzo de 1927, p. 1.

17 Véase sobre el particular Diana Sanz Roig (2011, pendiente de publicación).

${ }^{18}$ Cf. CMV, Cartes a la seva família (1903-1962), «Cartes al seu germà Joaquim» (44117), 30 de septiembre de 1927, Ms. 3138. Barcelona: Biblioteca de Catalunya. 
do el instrumento, sin tocar aún nada que valga la pena. Digo esto porque preferiría contar en Mundo Ibérico con una cantidad mensual, por un artículo también mensual, a celebrar alguna vez, aunque los honorarios fuesen mayores. Diga en la Administración que yo escribo muy gustoso para Vds. un trabajo mensual, en estas condiciones. 50 ptas. Tamaño, el normal, es decir, una columna y media o dos de $E l$ Sol $^{19}$.

La revista discurre sobre la Ley de Propiedad Intelectual y se muestra favorable a la institucionalización de un día que conmemore el libro como instrumento de cultura. La defensa del iberismo, que incluía el público portugués y americano, pero excluía el vasco como lengua peninsular, se hará sobre todo explícita en las referencias al país vecino ${ }^{20}$, y en el editorial que inaugura la revista del 5 de julio de $1927^{21}$, número que transmite ideas parecidas a las declaraciones de principios que abundaban sobre el particular en La Gaceta Literaria $^{22}$. A este respecto, y como indica Fuentes Mollá (1986: 32), el título de la revista no es accidental y recoge la voluntad integradora que caracterizó la personalidad de Verdaguer, pero también cierta nostalgia del imperio y el decidido empeño por reivindicar la amplia cultura hispánica. Por otra parte, la posición periférica de Verdaguer respecto al centro literario de la época podría explicar su determinación por dirigir una revista cultural que le mantuviera conectado con los escritores de Madrid ${ }^{23}$. Sobre su deseo de hermanarse con los pueblos de la cultura hispánica, muy explícito es el primer editorial:

Queremos [...] dedicar atención suma a nuestros pequeños pero interesantes territorios coloniales, y a cuanto se refiere a nuestra zona marroquí y a los problemas

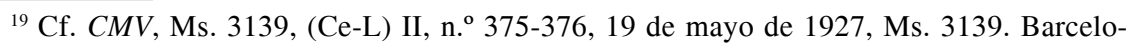
na: Biblioteca de Catalunya. El artículo de Jarnés es el siguiente: «Pauta y arabesco», Mundo Ibérico, 20 de julio de 1927, n. ${ }^{\circ}$ 4. Diez años después, Verdaguer conseguirá dos colaboraciones de Jarnés, hoy olvidadas, para el boletín bibliográfico de la editorial Apolo: «Goya y Baudelaire», Apolo. Revista de Bibliografía, marzo 1938, n. ${ }^{\circ} 3, \mathrm{y}$ «Un profeta sonríe», junio de 1938, n. $^{\circ} 4$.

${ }^{20}$ Cf. Enrique de Leguina, «Portugal y España», Mundo Ibérico, 1 de septiembre de 1927, n. ${ }^{\circ} 6$.

${ }^{21}$ «Pocos países podrán envanecerse de que una de sus revistas pueda adoptar semejante título. España, Portugal, y todos los pueblos de origen ibérico, lo justifican plenamente, ya que nuestro propósito es ocuparnos de las manifestaciones de la vida de la raza, estableciendo una fraternal solidaridad entre las diversas ramas de la gran familia ibérica». Cf. Anónimo (Mario Verdaguer con toda probabilidad), Mundo Ibérico, 5 de julio de 1927, n. ${ }^{\circ} 3$.

${ }^{22}$ En el prólogo a la edición facsímil (1980) recordaba Giménez Caballero: «Ibéricamente. Se redactaba en portugués, catalán y gallego -y aún intenté el vasco-, y con una «Gaceta Sefardí» o de rama ibérica para los judíos hispano hablantes. Fue la promotora de la Exposición del Libro Catalán en Madrid y del viaje de los intelectuales castellanos a Cataluña, resumido en mi libro Cataluña ante España. En cuanto a Portugal, también realizamos una Exposición y un viaje a Lisboa. Y para sefardíes, todo un ciclo de conferencias con una película mía sobre los «Judíos de Patria Española».

${ }^{23}$ Ródenas (2009: 432) se refiere a esta cuestión para explicar el escaso predicamento del autor. 
de las hermosas islas que bajo el pabellón español bañan sus costas en el Mediterráneo y el Atlántico ${ }^{24}$.

Publicación miscelánea, Mundo Ibérico se asemeja a la revista ilustrada (no es muy distinta de Blanco y Negro) e incluye reportajes de tipo cultural o de entretenimiento, como los dedicados a la gastronomía, el deporte, el cine, el turismo o los pasatiempos. Asimismo, también da a conocer relatos de Gómez de la Serna, Cristobal de Castro o María Luz Morales; artículos de Rafael Cansinos Assens, Estévez Ortega, Ciges Aparicio o Giménez Caballero; una novela de aventuras por entregas de Theo Varlett; reflexiones varias de José María Salaverría o Benjamín Jarnés; estampas de viaje o trabajos sobre la propiedad intelectual, los romances de ciego, el teatro de los hermanos Machado, el cincuenta aniversario de l'Atlàntida de Jacinto Verdaguer, la obra de Antoni Gaudí o la pintura de Francisco de Goya. Este eclecticismo se reflejará también en la sección «Galería artística», que reproduce láminas (similares a las que incluía la obra de Ballesteros de Martos, Galería de Maestros Españoles, publicada en Lux) de obras clásicas de Tiziano, Latour, Veronés, Van Dick, Rubens o Da Vinci, pero también de artistas modernos y de vanguardia como Salvador Dalí, Rafael Barradas, Torres-García o Miguel Viladrich, que Verdaguer había frecuentado en el restaurante Carbó. Igualmente, aparecen en la revista fotografías a gran formato de personalidades políticas, actores y actrices de la reciente industria cinematográfica; deportistas, y retratos de estudio de escritores y músicos como Gómez de la Serna, Cansinos Assens, José Francés, Pau Casals o Santiago Rusiñol, a quien había conocido en la tertulia palmesana La casa de los poetas. La revista contará también con la colaboración de ilustradores como Enrique de Ochoa, encargado de casi todas las portadas, y la participación del propio Verdaguer o Almada Negreiros, que contribuye con algunos dibujos — retribuidos con 100 pesetasgracias a la mediación de Ramón Gómez de la Serna. En este sentido, Mundo Ibérico cuidará, como anuncia en el primer editorial, los detalles gráficos que a su juicio tanto influyen en la impresión que causa en el lector ${ }^{25}$.

La costosa producción de sus páginas y la restringida difusión de la revista favorecieron no obstante el cierre de la misma. Para Gracia (2000: 25), Mundo Ibérico fue un producto cultural que ambicionó demasiado pronto un formato de revista que conciliaba intereses muy dispares. No obstante, si esta afirmación es válida en tanto que la revista quiso captar por igual al lector culto y al menos exigente, quizá debería matizarse si analizamos con detalle su información literaria. En términos generales, Mundo Ibérico se propuso publicitar las novedades de la editorial Lux y las obras que satisfacían el gusto

${ }^{24} \mathrm{Cf}$. Anónimo (Mario Verdaguer con toda probabilidad), «Al comenzar», Mundo Ibérico, 5 de junio de 1927, n. ${ }^{\circ}$ 1, 3. Como constata Santonja (1989: 19), este afán por reivindicar la «cultura hispánica» también se observa en la estrategia editorial de la gigante CIAP.

${ }^{25}$ Ibídem, 3. 
de Verdaguer y de su círculo de interesadas amistades, política que sólo podía condenar a la revista a la difusión minoritaria o a su desaparición. A este respecto, Mundo Ibérico, que en realidad fue poco progresista y manifestó escasa vocación de dinamizar el panorama cultural, no fue la revista que Verdaguer pareció imaginar. Una información literaria más objetiva y completa habría podido captar el interés de un público general, a la vez que habría conciliado distintos intereses y vitalizado el mercado literario-editorial. Redefinir la división del público lector y captar tanto al culto como al menos exigente, fueron propósitos que también quisieron alcanzar los proyectos editoriales de Lux y Apolo, pero su desarrollo tuvo quizá mayor éxito que el cosechado por la revista.

Sea cuál sea el alcance, las aventuras editoriales de Verdaguer reflejan sin duda un instinto de mercado, y es en este sentido llamativo que una figura de la brillantez de Gómez de la Serna viera en él, hoy rescatado a duras penas, el líder de la periferia en la búsqueda de lo moderno y de lo nuevo:

¿Cómo va esa vida intelectual barcelonesa que usted tiene que ser el que la coordine en un día no lejano? [...] Sigo creyendo en la nave que salga de ese puerto pilotado por usted (yo soy apenas un pasajero que se marea). La referencia de ecos entre este puerto (Lisboa) y ese puerto hace que les oiga y pueda pensar en todos con menos ceguera del metido entre tierras ${ }^{26}$.

En los años de la todavía escasa profesionalización del escritor, el acceso al gran público era un paso necesario para adquirir una posición central en el campo literario, y es este deseo, muy temprano en Verdaguer, escritor con vocación literaria pero consagrado al periodismo ${ }^{27}$, el que se pone particularmente de manifiesto en algunas cartas de su epistolario. En este sentido, discrepamos de la afirmación de Fuentes Mollà (1986: 18), que califica el ansia cultural de Verdaguer como de «apetencia intelectual desinteresada». Así, en carta a su familia del 10 de marzo de 1914, escribe en relación a su trabajo en el diario Las Noticias:

${ }^{26}$ Cf. $C M V$, «Cartas de Ramón Gómez de la Serna», 1 de noviembre de 1927?, Ms. 3139 (Ce-L) II, n. ${ }^{\circ}$ 353. Barcelona: Biblioteca de Catalunya.

${ }^{27}$ Verdaguer inició su carrera de periodista en el diario La Almudaina de Palma de Mallorca, colaboración que abandona cuando el crítico musical de La Publicidad, José María Pascual, le introduce en los órganos de prensa barceloneses más señalados de la época. Según cuenta en sus memorias (Verdaguer, 1957: 218), trabaja desde 1910 en el diario Las Noticias como redactor de telegramas de política, y en El Día Gráfico a partir de 1915, momento en el que despiden a Salvador Armet, su director y mecenas. En 1916 empieza a trabajar en La Vanguardia, donde su director, Miquel del Sants Oliver, le nombra secretario personal. Posteriormente, Verdaguer será redactor de la sección «Extranjero», en la que traduce los telegramas que enviaba la Agencia Havas. Verdaguer también aparece como director de la agencia «Radio», que se ocupaba de los telegramas e informaciones de todo el mundo, y se convierte en su crítico literario a partir de 1928. Al mismo tiempo, intentará sin éxito escribir sobre literatura catalana en el diario El Sol de Madrid, donde ya colaboraban Gaziel, Josep Carner, y Roque Guinart. 
Ahora empezaré a publicar artículos con mi firma hablando de los principales literatos catalanes lo cual me servirá, además de darme a conocer directamente con el gran público, para relacionarme con la gente de valía positiva, y hacer una labor que será simpática a la causa catalana, pues servirá para significarme dentro del movimiento actual. Me parece que empezaré publicando un artículo sobre Guimerà $^{28}$.

Y continúa en la misma carta:

No sabe las ganas que tengo de servir y de que mi nombre se vaya abriendo paso y salga del tono gris e igualitario de la muchedumbre. El camino es indudablemente penoso pero creo reunir condiciones suficientes para conseguirlo.

La actitud de Verdaguer, conscientemente ambivalente, coincide con la situación poco definida del escritor de su época, abocado a encontrar un público que permitiera su profesionalización sin enfrentarse con el gusto mayoritario de la $\operatorname{masa}^{29}$. Así se comprende su propósito de publicar alguna novela corta como Eva fuera del paraíso en «La Novela Mundial», colección popular que dirigía García Mercadal (que también escribirá en Mundo Ibéri$c o$ ), a la vez que trataba de publicar sin éxito en la elitista Revista de Occidente, tras la invitación de Jarnés y Fernando Vela. Su tarea de traductor, que se consolidará sobre todo en la década de los años treinta, le permite conjugar los dos polos de la estructura del campo editorial, ya que pese a su escasa profesionalización el traductor no sólo empieza a ser solicitado por el editor, sino que en algunos casos se busca a aquella figura que pueda prestigiar la colección, no sólo por su autoridad, sino por el estilo que pueda imprimir a la nueva traducción. No obstante, desde el punto de vista económico, es evidente que el traductor no podía subsistir de su exclusiva dedicación, y debía compensar esta tarea con otras actividades. Entre la disparidad de trayectorias profesionales que frecuentan la traducción cabe destacar a los traductores que contaban ya con cierta legitimidad - acreditada por su trabajo en la prensa, los círculos académicos y universitarios, o las instituciones y la vida política-, y los que por el contrario carecían de ella. Estos últimos, en muchos casos periodistas o escritores advenedizos, pretendían alcanzar la notoriedad a través de la traducción de autores consagrados, y es con esta voluntad con la que Verdaguer accederá al mundo editorial ${ }^{30}$.

${ }^{28}$ Cf. CMV, Cartes a la seva família (1903-1962), «Als seus pares i germana Teresa» (1-43), 10 de marzo de 1914, Ms. 3138, n. ${ }^{\circ}$ 11. Barcelona: Biblioteca de Catalunya.

${ }^{29}$ Sobre las todavía difíciles condiciones profesionales del periodista, resulta muy interesante una carta de 1920 que Verdaguer escribe justo un día después de haber firmado un contrato con el Conde de Godó, propietario de La Vanguardia: «ayer firmé un contrato de trabajo con el propietario, el cual se comprometió a lo siguiente: a aceptarme como redactor del diario, a darme un sueldo de 220 ptas. mensuales con la procura de futuros aumentos, a no sacarme del periódico mientras yo no falte a mi honorabilidad; a abonarme el sueldo íntegro en caso de enfermedad por larga que sea esta; a jubilarme con el sueldo que disfrute 


\section{LA EDITORIAL LUX}

A diferencia de otras iniciativas similares, los proyectos editoriales de Lux y Apolo son todavía poco conocidos pero ilustran a la perfección las características indisociables entre la empresa comercial y la empresa cultural. Lux, propiedad del librero Juan Balagué, responsable también del impulso de Mundo Ibérico y de la Librería Central, en la calle Muntaner 42, se inclinó decididamente por las obras de consumo, y privilegió sobre el valor literario el criterio económico y comercial. Su política editorial, subordinada a las transformaciones del mercado literario español y a la aparición de un nuevo público lector, se basó en formatos populares, poco destacados literariamente, que incluían en su catálogo compendios de salud, higiene, cocina, belleza y hogar; un corpus de derecho civil romano, y una de sus colecciones bandera «La Novela Mensual». Verdaguer, asiduo invitado a las reuniones del editor, se convertiría en su director literario en $1924^{31}$.

Tras el descalabro de la Primera Guerra Mundial, un mercado editorial todavía puro se convertía en un objeto de conquista. El negocio de las colecciones y fórmulas populares tenía como resultado el acceso inmediato al centro del mercado, que no implicaba sin embargo la adquisición de una posición central desde el punto de vista del capital cultural o simbólico. Como indica Justo Arévalo (2000: 108), una de las primeras empresas editoriales que se asentó en esta tendencia fueron las Publicaciones Mundial, que no sólo anhelaban el rédito económico sino hallar acomodo en el espacio editorial español con un proyecto ambicioso y diversificado ${ }^{32}$. Lux publicará «La Novela Mensual» entre 1924 y 1928, fecha en la que por motivos económicos

por edad o enfermedad. Yo a cambio de esto me obligo a amoldarme a la organización actual del trabajo y a no pertenecer al sindicato mientras este no esté reconocido por la ley». Cf. CMV, Cartes a la seva família (1903-1962), «Als seus pares i la seva germana Teresa» (143), 6 de enero de 1920, Ms. 3138, n. ${ }^{\circ}$ 30. Barcelona: Biblioteca de Catalunya.

${ }^{30}$ Verdaguer así lo reconoce en una carta a su hermana Teresa Verdaguer Travesí, fechada el 1 de septiembre de 1925: «Ahora tengo mucho trabajo. Estoy traduciendo una novela para una casa editorial, esto me ocupa muchas horas. Además me dedico en serio a la literatura». Cf. CMV, Cartes a la seva família (1903-1962), «Als seus pares i a la seva germana Teresa» (1-43), 1 de septiembre de 1925, Ms. 3138, n. ${ }^{\circ}$ 36. Barcelona: Biblioteca de Catalunya.

${ }^{31}$ Cf. López Antuñano (1992: 10).

${ }^{32}$ Detrás de esta iniciativa hallamos al impresor Félix Costa, instalado en su taller tipográfico de la calle Nou de la Rambla, también conocida como Conde del Asalto. Costa será el responsable de algunas publicaciones periódicas de tipo popular como La Rambla (1914), La Baldufa (1914-1915) o Teatro Mundial. Suplement (1914). También será el impresor de las publicaciones de filiación republicana o lerrouxista El Progreso. Ilustración Republicana (1909-1910), La Rebelión (1910-1911), Vida Radical (1912), La Protesta (1912) o La Ira (1913), e incluso del semanario catalanista Cu-Cut! (1913-1914), y del Papitu a partir de 1916 y hasta su cierre en 1937. Tomamos los datos de Arévalo (2000: 109). 
traspasa una parte de su fondo a Publicaciones Mundial, que retomará la colección al año siguiente ${ }^{33}$. Según Arévalo (2000: 108), Lux será responsable de los veinticinco primeros volúmenes, que se imprimirán en el taller de La Ibérica; los dos últimos, -Un perro de circo (1928), de Jack London, y Buena amiga (1928), de Paul Rouget_ ya se imprimirán en el taller de Santiago Costa, propietario de Publicaciones Mundial ${ }^{34}$. Desde ese momento, la empresa del editor Costa, instalada desde 1926 en el número 201 de la misma calle Consejo de Ciento, se encargará de la colección, que se ampliará hasta el volumen treinta y uno.

«La Novela Mensual» publicó al castellano traducciones de calidad desigual y alguna obra de producción local. Con preferencia por la novela rosa y el género sentimental, esta colección ecléctica se dirigió a un público esencialmente femenino, que adquiría las novelas en los quioscos por 1 peseta, 2 a lo sumo, ante el sugerente eslogan «una colección de novelas selectas que leerá con gusto». Atenta a los éxitos literarios franceses, y con vistosas portadas, «La Novela Mensual» dará a conocer las obras de Guy Chantepleure, Éveline Le Maire, Jules Sandeau, Georges Ohnet o Adolphe de Falgairolle (colaborador de Mundo Ibérico), pero también las de los anglosajones y alemanes Berta Ruck, Eugenie Marlitt, Charlotte Braeme y un ficticio Abel King, que es en realidad Mario Verdaguer, como se deduce de una carta escrita a su hermano Joaquín:

Te mando también una novelita titulada La casa de las pulgas de un supuesto inglés que reside en Barcelona. Ha obtenido un gran éxito de venta, más de cinco mil ejemplares desde que ha aparecido. Pertenece a una colección en la cual intervengo y en esta novela lo he hecho precisamente de un modo muy directo. Es simplemente un juego de imaginación, sin valor literario, e indigna de ser firmada con un nombre. A pesar de esto es ahora lo que gusta. Si encuentras alguna novelita de este género, en inglés o alemán, dímelo y entonces podrías hacer la traducción que te sería pagada en treinta o cuarenta duros. Como aparece un tomo cada mes nos encontramos a veces faltos de original y es preciso apelar al camelo, que a veces sale bien como las pulgas ${ }^{35}$.

${ }^{33}$ La fuerte competencia de la editorial Juventud, que incluía también en su catálogo una colección de novela rosa en la que aparecían muchos de los autores de «La Novela Mensual», puede aventurarse como uno de los motivos que precipitó la venta de parte de su fondo.

${ }^{34}$ Santiago Costa, hijo del impresor Costa, heredó de su padre Publicaciones Mundial, y se instaló en la calle Barberà número 15, a partir de mayo de 1921, con el propósito, según indica Arévalo (2000: 112), de monopolizar el mercado editorial barcelonés de gran consumo. Así es como el joven editor emprende la diversificación de la oferta de sus colecciones, y absorbe aquellas empresas que sufrían problemas económicos. Entre sus colecciones, «Biblioteca Actualidad», «La Novela de Actualidad», «Los Bajos Fondos de Barcelona», «La Novela Popular Cinematográfica», «La Novela Femenina» o «La Novela del Pueblo».

${ }^{35}$ CMV, Cartes a la seva família (1903-1962), «Cartes a Joaquim Verdaguer», 7 de julio

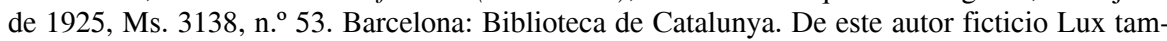
bién publica en 1927 La novela de un guardameta, traducida según consta en el libro por A. Reyes. En efecto, podría tratarse de Alfonso Reyes, si bien no hemos podido confirmar este dato ni en la página web dedicada al autor ni en los volúmenes de sus Obras Completas. 
En efecto, parece probable que Verdaguer extendiera esta práctica a otros títulos de la colección, indocumentados en Palau i Dulcet (1948-1977), y en los catálogos de la Biblioteca Nacional de España, la Biblioteca de Catalunya o la Biblioteca Nacional de París. La oposición entre lo comercial y lo no comercial también se traduce en la diferencia que existe entre la producción que niega el provecho económico e ignora las expectativas del público (creando la demanda que ella misma constituye), y aquella que se asegura el éxito y los beneficios con el público y la demanda que ya existía. «La Novela Mensual» se acoge a este último modelo y es en este sentido que el propio Verdaguer le propone a su hermano Joaquín, en carta del 15 de octubre de 1929, la sugerente escritura de una obra espiritista, que atribuirán a un falso doctor alemán ${ }^{36}$. Para ello, le sugiere que se documente en la revista Psychische Studien: Monatliche Zeitschrift, que él mismo le enviará. A este respecto, es verosímil pensar que junto a Enrique de Leguina, o el propio Verdaguer, su hermano menor fuera también el responsable de muchas de las traducciones de las novelas de la colección, tal y como insinúa el propio escritor menorquín:

he recabado del editor lo siguiente: que toda obra inglesa que publiquen en la mensual hagas tu la traducción. (...) Toda novela blanca, que sea interesante, alemana o inglesa, interesa mucho. Si encuentras algo mándame enseguida el título y un pequeño resumen del argumento. Nosotros miraremos entonces si ya está traducida, y en el caso de que no lo estuviese, te encargaríamos enseguida la traducción. (...) Creo que puedes convertirte en el traductor oficial de la casa. El editor está completamente a mis órdenes en este terreno. Te pagará muy bien. Ya ves que daba 200 pesetas por una traducción tan corta como la de El León ${ }^{37}$.

«La Novela Mensual» continuará con la tendencia en boga de las colecciones de novela corta que se habían estrenado en España bajo el impulso de la madrileña «La Novela Corta»(1916-1925), de José de Urquía, y de «La Novela Semanal»(1921-1925), publicada por Prensa Gráfica. Director literario de la editorial Lux en sus años de periodista y escritor primerizo, Verdaguer tratará de introducir, si bien tímidamente, algunas calas de nueva o alta literatura. Así es como junto a los populares Sandeau, Ohnet, Champol o Chantepleure, hallamos escritores clásicos como Lamartine o George Sand (cuyo éxito duradero se oponía al efímero de los best-sellers), y producciones nacionales como las de Enrique de Leguina, secretario de Mundo Ibérico; María Luz Morales, compañera de redacción en La Vanguardia, o Tomás Orts-Ramos, autor de numerosos trabajos en torno al mundo taurino.

\footnotetext{
${ }^{36}$ Joaquín Verdaguer trabajó como traductor a lo largo de toda su vida, aunque su tarea principal la realizaba en el Instituto Ramon Llull, como profesor de inglés, y en la Escuela Superior de Comercio, como profesor de alemán. Mario Verdaguer (1964: 12) así lo recuerda en la semblanza «Mario y Joaquín Verdaguer, vistos el uno por el otro».

${ }^{37}$ CMV , Cartes a la seva família (1903-1962), «Cartes a Joaquim Verdaguer», 15 de octubre de 1929, Ms. 3138, n. ${ }^{\circ}$ 88. Barcelona: Biblioteca de Catalunya.
} 
El librero Juan Balagué ${ }^{38}$, dueño de la parte del fondo que no pertenecía a Publicaciones Mundial, pretenderá, con el consejo de Verdaguer, acceder a un público más numeroso. A sugerencia del escritor menorquín, Lux publicará la serie «Grandes éxitos literarios», que incluye experimentos vanguardistas como su propia novela El marido, la mujer y la sombra (1927), o la anterior La isla de oro (1926); traducciones de autores europeos consagrados como Panaït Istrati, de quien se publica Kyra Kyralina, pero también Los Aiducs y Domnitza de Sganov, en versión de Joaquín Verdaguer, y, al mismo tiempo, libros de viajes o novelas para señoritas. En este sentido, como señala Sánchez Álvarez-Insúa, es característica de la época la coexistencia de notables y escritores populares (1996: 26) y se trata, en definitiva, de dosificar el riesgo, publicando a la par novelas comerciales y apuestas de futuro. El epistolario de Verdaguer pone de manifiesto las numerosas propuestas que el escritor menorquín recibe como director literario. Por la calidad de sus autores cabe destacar las sugerencias de Cansinos Assens, que le recuerda su don políglota, o Gómez de la Serna, que le propone publicar una edición barata de su novela El Gran Hotel:

Mis pretensiones no serán muchas porque sobre todo quiero que se lea y circule en una edición bastante popular. Es de mis novelas la que menos ha circulado. Usted me dirá francamente lo que puede hacerse y en último caso ahí le queda un ejemplar de reconocimiento y amistad $^{39}$.

Cansinos Assens, a su vez, comentaba las dos novelas de Verdaguer publicadas en Lux en el último tomo de La nueva literatura (1927). Con un precio más elevado —entre 3 y 5 pesetas—, respecto a los volúmenes de «La Novela Mensual», la nueva serie — «Colección Lux»— se anunciará en la revista Mundo Ibérico con el reclamo «Novelas todas ellas de un gran valor literario y amena y culta lectura», y de ella se da noticia en las páginas de la publicación. Los cuatro primeros títulos de esta colección son: El Apocalipsis, de Pierre Dominique; La reina del Chaco, de Ciro Bayo; La vida de Franz Liszt, de Guy de Portalès, y la novela de Gómez de la Serna. El folleto de propaganda que distribuye la editorial incluye un dibujo de Rafael Barradas.

Las diferencias con respecto al precio y al público serán dos de los aspectos que distinguirá «La Novela Mensual» de las colecciones de la editorial Apolo, cuyos volúmenes, si bien publicados años más tarde, oscilarán entre las 6 pesetas, el volumen más económico, y las 27, el más costoso ${ }^{40}$.

${ }^{38}$ Después de la guerra, Balagué será el responsable de la Sala Mauricio Vilomara, ubicada en el mismo local de la Librería Central, y reiniciará el contacto con Mario Verdaguer, instalado en Palma de Mallorca, que le proporcionará algunos cuadros para exponer o vender en subasta.

${ }^{39}$ Cf. $C M V$, «Cartas de R. Gómez de la Serna», Ms. 3139 (Ce-L) II, n. ${ }^{357 . ~ B a r c e l o n a: ~}$ Biblioteca de Catalunya.

${ }^{40}$ Mi amigo Robespierre, de Henri Béraud, valía 7 pesetas encuadernado en rústica; el Danton, de Jacques Roujon, 8; el Gog, de Papini, 7; El socialismo, de Durkheim, 10, en 


\section{LA EDITORIAL APOLO}

Como reconoce abiertamente Manuel Llanas (2005: 313), todas las tentativas realizadas para averiguar el origen y la trayectoria de la editorial Apolo han resultado hasta ahora infructuosas. Para este profesor, Apolo constituye un paradigma del enorme déficit de información que acumula la historia de la edición, dominio al que este trabajo pretende contribuir modestamente. $\mathrm{Si}$, en efecto, pocos datos conocemos de la creación de esta editorial, la información que nos proporciona el epistolario de Mario Verdaguer nos permite reconstruir una parte de su historia, y aclara algunos puntos sobre los que se interroga Llanas (2005: 313):

(Apolo) Devia néixer a finals dels anys 20, n'era propietari Emili Pascual (de qui ho desconec tot) i passa successivament per dos domicilis: el 16 del carrer Flors i el 7 del passatge Marimon. Em fa l'efecte que, el gran moment, l'Editorial Apolo el viu durant la Segona República, etapa en què dóna a conèixer els títols més rellevants i en què hi colllaboren (com a autors, traductors, curadors i prologuistes), Màrius Verdaguer i Ramon Esquerra, el qual no m'estranyaria que hi exercís alhora la direcció literària. A partir d'abril de 1932, la casa publica Apolo. Revista de bibliografía, un butlletí aparentment mensual que continua apareixent durant la guerra i que conté ressenyes de novetats editorials pròpies, articles de crítica i una crònica de l'actualitat literària internacional. L'interès de l'exigua producció de l'Editorial Apolo en aquests anys (una cinquantena de títols) ve donat per la talla dels autors i de les obres traduïdes, especialment de l'alemany.

Emili Pascual i Monturiol (1890-?), nieto de Narcís Monturiol como apunta el propio Verdaguer, fue un dibujante humorista del primer tercio del siglo XX que colaboró en los decenios de 1910 y 1920 en algunos seminarios satíricos como L'Esquella de la Torratxa ${ }^{41}$. De estilo grotesco, Pascual firmó sus ilustraciones con los pseudónimos «Pal» $\mathrm{y}$ «Miliu», y abandonó el dibujo para dedicarse a otras actividades mercantiles como la metalurgia o la edición. Con motivo de la traducción de La Lucha contra el demonio, de Stefan Zweig, a él se refiere Verdaguer en carta a su hermano Joaquín del 24 de mayo de 1933:

Me parece que ellos prefieren, después de lo que les he dicho, que traduzcas la Lucha contra el demonio, que es mucho más difícil y extenso que la María Antonieta, puramente histórica. En seguida que llegue el permiso te mandarán el libro. El propietario de la casa, Don Emilio Pascual Monturiol, nieto de inventor, es una persona bondadosísima ${ }^{42}$.

rústica, y 13 encuadernado en tela, y La curación por el espíritu, de Zweig, 20 pesetas, encuadernado en tela.

${ }^{41}$ Cf. José F. Ràfols (1951-1954).

${ }^{42}$ Cf. CMV, Cartes a la seva família (1903-1962), «Cartes a Joaquim Verdaguer», 24 de mayo de 1933, Ms. 3138, n. ${ }^{\circ}$ 108. Barcelona: Biblioteca de Catalunya. 
Responsable de la fabricación de navieros para la compañía Transatlántica, el propietario de Apolo, «gente encantadora y muy culta que creen que hacer libros vale más que hacer barcos aunque la cosa de menos dinero ${ }^{43}$, fue uno de los primeros empresarios metalúrgicos de Cataluña. Estrecho colaborador de la compañía marítima, empresa que no por casualidad se publicitaba en las páginas de Mundo Ibérico, el negocio de la familia Pascual se vio profundamente afectado por la rescisión del contrato que el gobierno mantenía con esta empresa. Como explica Verdaguer, esta situación perjudicó enormemente al negocio de la familia Pascual que al cabo de dos meses se declaró en suspensión de pagos:

El amigo Susanna (Francisco Susanna) me recibe con la cara larga y triste y me comunica que los grandes talleres de metalurgia de los propietarios han declarado la suspensión de pagos por no haber podido resistir el golpe de la Transatlántica y que la Editorial, por ser negocio de ellos también, ha entrado a formar parte de la masa sobre la cual se han echado encima los acreedores. Era absolutamente imposible pagar, ni siquiera una cantidad a cuenta por pequeña que fuese, pues los interventores habían cerrado en absoluto la caja. Parece que esta medida era debida a que más que una suspensión de pagos la cosa presentaba el aspecto de una quiebra de algunos millones de pesetas. Vi a uno de los propietarios, don Emilio, y sólo con verle tuve toda la noción de la magnitud de la catástrofe ${ }^{44}$.

Susanna, de quien apenas tenemos noticia ${ }^{45}$, fue el director de la editorial y autor de numerosas traducciones, si bien su buena relación con Verdaguer, que apreciaba la seriedad y el tesón de la casa editorial, favoreció con el paso del tiempo la ascendencia de éste último ${ }^{46}$. En este sentido, y tomando en consideración que la literatura alemana es uno de los ámbitos más atendidos (Llanas, 2005: 313), parece probable que Verdaguer se convirtiera en su director literario a principios de los años treinta, ya que varios de los títulos de la editorial responden bien a sus intereses literarios ${ }^{47}$. Como se lee en uno de los primeros catálogos, Apolo aspiraba a «satisfacer los nobilísimos anhelos del público que lee», y a incorporar al acervo literario «todos aquellos auto-

${ }^{43}$ Cf. CMV , Cartes a la seva família (1903-1962), «Cartes a Joaquim Verdaguer», 25 de mayo de 1932, Ms. 3138, n. ${ }^{\circ}$ 102. Barcelona: Biblioteca de Catalunya.

${ }^{44}$ Cf. CMV, Cartes a la seva família (1903-1962), «Cartes a Joaquim Verdaguer», 17 de julio de 1932, Ms. 3138, n. ${ }^{\circ}$ 103. Barcelona: Biblioteca de Catalunya. Véase también carta del 25 de mayo de 1932, n. ${ }^{\circ} 102$.

${ }^{45} \mathrm{Su}$ nombre no figura ni en el reciente Diccionario histórico de la traducción en España (2009), ni en la base de datos World Biographical Information System.

${ }^{46}$ A Susanna se refiere Verdaguer en carta a su hermano: «yo me he hecho muy amigo de uno de esos señores que me tiene en gran consideración, Francis Susanna, el director de la editorial es un hombre charmant y de una cultura extraordinaria».Cf. CMV, Cartes a la seva família (1903-1962), «Cartes a Joaquim Verdaguer», 25 de mayo de 1932, Ms. 3138, n. ${ }^{\circ}$ 102. Barcelona: Biblioteca de Catalunya.

${ }^{47}$ La literatura alemana fue, no cabe olvidarlo, la que también dominó los índices de una editorial de avanzada como Cenit (1928-1936) (Santonja, 1989: 61). 
res de universal prestigio (...) cuyas obras, bien por su actualidad, bien por sus méritos intrínsecos, habían de merecer la más excelente acogida $\gg^{48}$. La distribución de la literatura española y las literaturas extranjeras es la siguiente: $22 \%$ para la literatura española y alemana; $20 \%$ para la francesa; $11 \%$ para la inglesa; $10 \%$ para otras literaturas; $9 \%$ para la rusa y $6 \%$ para la literatura italiana.

No obstante, a diferencia de lo que opina Llanas (2005: 313) sobre el papel de Ramon Esquerra, nos inclinamos a pensar que el crítico catalán desempeñó un rol determinante en el impulso de los «Manuales de Iniciación» (a semejanza de los que había publicado Maucci), y también en la elección de algunos autores, pero dudamos, en cambio, de la dirección literaria que le atribuye Llanas. A este respecto, la posición predominante de la literatura alemana parece indicar la dirección de Verdaguer y, en menor grado, la de Esquerra, que cabe recordar privilegió como profesor del Instituto Francés de Barcelona el estudio de la literatura francesa y anglosajona. Esquerra también participó en el boletín bibliográfico Apolo. Revista de bibliografía ${ }^{49}$ que publicó la editorial para promocionar su catálogo a partir de 1932, y que cuenta con un sólo número en esta primera etapa, y con siete más entre 1937 y 1939. La revista se anunciaba con el siguiente eslogan: «Si es Vd. amante de los buenos libros, lea la revista APOLO, que recibirá Vd. gratuitamente todos los meses».

Con respecto a la fecha de su creación, es probable que Apolo se fundara en la primera mitad de 1929, ya que sabemos por el epistolario de Verdaguer que el escritor menorquín estaba traduciendo un libro del francés y otro del alemán en julio del mismo año, tras aceptar la propuesta del editor que le invitaba a ser uno de los traductores de su casa ${ }^{50}$. El domicilio de Apolo parece ubicarse en los primeros años en la calle Flors, número 16. A partir de 1937, la editorial se trasladará al Passatge Marimon, número 7. Llanas (2005: 313) señala las fechas de 1951 o 1953 como el momento en el que Janés consigue absorber el fondo de Apolo. No obstante, si tenemos en cuenta la fecha en la que concluyen sus colecciones clásicas, ya deberíamos tener presente el año de 1948 como momento que marca el declive de la editorial. De este año es la última entrega, de la que tenemos noticia, de los «Manuales de Iniciación»(Elementos de Economía Moderna), y de fechas no muy lejanas son las últimas traducciones de nuevos títulos de Francisco Susanna y Mario Verdaguer, en 1945 y 1946, respectivamente. Por otra parte, y después de haber consultado el catálogo de la editorial, se observa un notable vacío de

\footnotetext{
${ }^{48}$ Cito por Llanas (2005: 313).

${ }^{49}$ Cf. Ramon Esquerra, «Consideración de la novela inglesa actual», Apolo. Revista bibliográfica, segunda época, octubre de 1937, n. $^{\circ} 1$.

${ }^{50}$ Cf. CMV, Cartes a la seva família (1903-1962), «Cartes als seus pares i germana Teresa» (1-43), 19 de julio de 1929, Ms. 3138, n. ${ }^{\circ}$ 43. Barcelona: Biblioteca de Catalunya.
} 
nuevas propuestas entre 1948 y 1951, momento en el que la actividad de la editorial parece retomarse con la colección «Prisma». Esta serie reeditará en 1949 Palabras y sangre y Dante vivo, de Papini, en traducción de Mario Verdaguer, y parece no prolongarse más allá de 1953.

Según Llanas (2005: 314-315), Apolo contaba en 1938 con seis colecciones: «Manuales», «Psicoanálisis y Antropología», «Sociología y Ensayos», «Biografías», «Grandes Novelas» y la «Biblioteca Freya», lista a la que habría que añadir la colección «Azor», de 1939 a 1940, que se inspiraba en el título y sus preferencias en la intermitente revista Azor de Luys Santa Marina; la colección «Boj» (1944), literatura de aventuras editada con sobrecubiertas en boj, y la colección «Prisma», a partir de 1949.

«Psicoanálisis y Antropología» acull quatre obres, entre les quals dues de Carl Jung i Alfred Adler. La tercera, «Sociología y Ensayos», alterna clàssics del pensament (Th. Moore, George Berkeley, o Émile Durkheim) amb autors del moment (Berdaiev, Lev Trotski o Bertrand Russell). La quarta, «Biografías», descansa en Stefan Zweig, autor de la majoria. La cinquena, «Grandes Novelas», incorpora Th. Mann, Arthur Schnitzler o Papini (Gog, amb 13 edicions el 1938, sembla el best seller de la casa). I la sisena, «Biblioteca Freya», consta d'una desena de petits volums de narrativa curta (Zweig, Huxley, o Lajos Zilahy). (Llanas 2005:315)

En la elección de los autores y obras traducidas se advierte también el consejo de Férenc Oliver Brachfeld (1908-1967) ${ }^{51}$ —escritor, traductor, y director de la revista Europa. Revista mensual internacional- que será el responsable de las primeras traducciones de literatura húngara —Lajos Zilahy, Endre Németh o muy tempranamente Sándor Márai-, y de la difusión de algunos autores de la escuela del psicoanálisis. Brachfeld traducirá en 1935 la Teoría del psicoanálisis, de Jung, y se interesará por los trabajos de Alfred Adler, cuyas teorías fueron tema de encendida discusión entre el crítico húngaro y Gregorio Marañón ${ }^{52}$. Aparte de su interés por el psicoanálisis, que

${ }^{51}$ Médico de carrera, Brachfeld se instaló en Barcelona en 1929, después de haber terminado sus estudios en Viena junto a Alfred Adler. Casado con Maria Bages, Brachfeld se dispuso a preparar su tesis doctoral Referencias a Hungría en la literatura catalana antigua y las baladas populares catalanas, al mismo tiempo que colaboraba en numerosos semanarios y prensa barcelonesa. Brachfeld regresó a la ciudad condal en 1931, después de haberse doctorado en Filosofía y Letras por la Universidad Pázmány Péter de Budapest y tras haber finalizado sus estudios en la Sorbonne y en el Instituto Católico de París. En 1936 se trasladó a Francia para volver brevemente a Cataluña en 1942. Tras varios años en la capital francesa, emigró a Venezuela en 1949. Sobre la figura de Brachfeld puede consultarse Ibarz y Villegas (2002), y Llanas y Pinyol (2009). Sobre su colaboración con Verdaguer véase Sanz Roig (2010).

${ }^{52}$ La discusión se inició en 1931 en la Revista Médica de Barcelona con el artículo «Crítica de las teorías sexuales de Marañón». El texto, publicado en 1929 en Zeitstschrift für Sexualwissenschaft, rebatía las teorías del médico español y denunciaba que su artículo no hubiera sido admitido en un concurso organizado por La Gaceta Literaria. Todavía en 1933, y tras la publicación del libro sobre Amiel, Brachfeld continúa rebatiendo las tesis de 
en el caso de Verdaguer se pone sobre todo de manifiesto en algunas de sus novelas - La mujer de los cuatro fantasmas y El intelectual y su carcoma, en particular-, Verdaguer y Brachfeld compartieron el gusto por la novela intelectual alemana, participando ambos en la celebración del sesenta aniversario de Thomas Mann, en el Ateneo de Barcelona ${ }^{53}$, en junio de 1935, o en la divulgación de algunos escritores como el popular Jacob Wassermann o Stefan Zweig, de origen austríaco. De hecho, si analizamos en el tiempo la presencia de la literatura alemana en las distintas colecciones de la editorial nos percataremos en seguida del vacío que se produce a partir de 1943, cuando Verdaguer se instala en Palma de Mallorca para trabajar en una empresa de seguros y la literatura alemana desaparece prácticamente del catálogo de la editorial $^{54}$. A partir de 1951 , la colección «Prisma» reeditará las obras de Zweig en traducción de Francesc Payarols y Joaquín Verdaguer, y la literatura en esta lengua - Zweig, Freud, Wasserman o Schenzinger- experimenta una fuerte recuperación.

El caso de Zweig es particularmente interesante para ilustrar el influjo de algunas colecciones francesas como «Le Cabinet Cosmopolite», colección que dirigía Edmond Jaloux en la Librairie Stock, y que publicó entre 1927 y 1934 todas las obras de Zweig, que también aparecerán en la editorial Apolo. Igualmente, parece probable que interesaran a Verdaguer los títulos publicados en Hachette o en la colección «Les Prosateurs étrangers modernes», de la editorial Rieder. En el caso de «La Novela Mensual», de Lux, es la francesa Calmann-Levy la editorial extranjera que suscita mayor interés.

Verdaguer, sin embargo, recibirá el consejo de otros autores como Cansinos Assens, que en carta del 17 de octubre de 1927 le propone reeditar Óscar Wilde y yo, de Lord Douglas (réplica del De profundis de Wilde), y la traducción de algunas obras breves de Kalidasa como el Sankuntala ${ }^{55}$. La propuesta, sin embargo, no se hará efectiva hasta catorce años después, cuando aparece en la editorial Apolo, y no en Lux como proponía Cansinos Assens, El reconocimiento de Sankuntala (1941), adaptada por Farran y Mayoral. Verdaguer también le propondrá a su hermano Joaquín la traducción del alemán de una antología de cuentos judíos, prologada por el escritor sevillano:

Marañón desde su tribuna en la revista Mirador («Comentaris a un llibre recent. L’Amiel del Dr. Marañón», 07-I-1933, 8). Como explican Ibarz y Villegas (2002: 268), Brachfeld publicó en 1933 el libro Polémica contra Marañón, obra que por su osadía suscitó un intenso debate en las páginas de la prensa de la época. El texto se acompañaba de una «Crítica de las teorías sexuales de Marañón», una réplica del médico español, y un epílogo.

${ }^{53}$ Según López Antuñano (1992: 15), Verdaguer fue admitido como socio residente el 29 de marzo de 1929, a propuesta de Juan Gutiérrez Gili, Josep Maria Capdevila y Josep Navarro Costabella.

${ }^{54}$ Verdaguer vuelve a casarse en 1945 y colabora en la revista Destino gracias a Ignasi Agustí. Asimismo, trata de continuar su tarea de traductor.

${ }^{55}$ Cf. $C M V$, «Cartas de R. Cansinos Assens», 17 de octubre de 1927, Ms. 3139-I (ACA), n. ${ }^{\circ}$ 182. Barcelona: Biblioteca de Catalunya. 
Creo muy oportuna la publicación de ese tomo de cuentos judíos que usted está traduciendo y desde luego sería para mí un alto honor prologarlo, según me indica. Pero sería menester que usted me diera detalles de los autores y los argumentos, para que yo pudiera documentarme. No sé si sabrá usted que en castellano se han publicado una antología talmúdica - Las bellezas del talmud- - y un volumen titulado Cuentos judíos, traducción y prólogo de este su servidor. Ambos libros vieron la luz en la Editorial América de Blanco Fombona, allá por el 1923. Veo que en esa editorial hay gran movimiento y me permito recordarle mi don políglota, por si halla oportunidad de reservarme alguna traducción interesante ${ }^{56}$.

Rieder, en efecto, también se había interesado por la literatura talmúdica publicando años antes la Anthologie des conteurs yidisch ${ }^{57}$.

Traductor del francés, el alemán, el italiano y el portugués, y dotado de ciertas nociones de japonés, Verdaguer será el responsable de todas las traducciones de Papini, que por cierto no aceptaba a otro traductor; de algunos textos de Zweig, autor estrella de la editorial; de La vida y la muerte del capitán Renaud, de Alfred de Vigny; de Napoleón de Teixeira de Pascoaes, o de La montaña mágica de Thomas Mann. Las obras de Zweig — La lucha contra el demonio y Tres poetas de su vida - también serán traducidas por Joaquín Verdaguer, que como en el caso de «La Novela Mensual» se beneficiará de la mediación y de los contactos de su hermano. La obra María Antonieta, para la que Apolo había también pedido los derechos de traducción, será finalmente traducida por Ramón $\mathbf{M}^{\mathrm{a}}$ Tenreiro en la editorial Juventud, que era para Verdaguer la única editorial que disfrutaba de cierta solvencia. En el caso de la traducción de La montaña mágica de Mann, la correspondencia de los hermanos Verdaguer nos proporciona algunos datos interesantes:

Estoy metido en la traducción de Der Zauber Berg de Thomas Mann, novela maravillosa que sólo tiene el defecto de ser más larga que el Quijote, lo cual te dará la medida de lo que hay que trabajar. Tengo también otra obra de Papini que hará pareja con Palabras y Sangre y que he tenido que aceptar también y comprometerme a terminarla pronto, pues el nervioso Papini está ansioso de verse vertido al español y al mismo tiempo exige que sólo yo le traduzca las obras ${ }^{58}$. He recibido la novela de Martínez Ferrando. Hay una coincidencia que me ha hecho gracia. Estoy traduciendo «La montaña mágica» de Thomas Mann. No sé si conoces esta larguísima obra maestra. La acción pasa en un sanatorio de Suiza. Es algo terrible y maravilloso. Los personajes son médicos o tuberculosos. La obra de Martínez Ferrando pasa en Suiza, médicos y tuberculosos. Martínez Ferrando haciendo la competencia a Thomas Mann es algo verdaderamente deleitoso ${ }^{59}$.

${ }^{56}$ Cf. $C M V$, «Cartas de R. Cansinos Assens», 22 de junio de 1927, Ms. 3139-I (A-CA), n. ${ }^{\circ} 182$.

${ }^{57}$ Cenit había publicado una antología en 1929 traducida del francés por J.G. Gorkin. El editor, Raymond Geyger, lo había hecho previamente en la Nouvelle Revue Française, 1924.

${ }^{58}$ Cf. CMV, Cartes a la seva família (1903-1962), «Cartes al seu germà Joaquim» (44-117), 22 de abril de 1932, Ms. 3138, n. ${ }^{\circ}$ 101. Barcelona: Biblioteca de Catalunya.

${ }^{59}$ Cf. CMV, Cartes a la seva família (1903-1962), «Cartes al seu germà Joaquim» (44-117), 25 de mayo de 1932, Ms. 3138, n. ${ }^{\circ}$ 102. Barcelona: Biblioteca de Catalunya. 
La quiebra económica de la editorial, vinculada como se ha descrito a los talleres metalúrgicos de los propietarios y a la compañía Transatlántica, afectó también el cobro de la traducción de La montaña mágica, que como explicita Verdaguer debía recompensarse con la cantidad de 3.000 pesetas.

Me puse a trabajar como un negro en una obra que es más larga que el Quijote y hace unos ocho días me presenté en la Editorial Apolo, lleno de la satisfacción del que ha realizado un esfuerzo y va a recoger el fruto (tenía que cobrar tres mil pesetas por la traducción). El amigo Susanna me recibe con la cara larga y triste y me comunica que los grandes talleres de metalurgia de los propietarios han declarado la suspensión de pagos por no haber podido resistir el golpe de la Transatlántica y que la Editorial, por ser negocio de ellos también, ha entrado a formar parte de la masa sobre la cual se han echado encima los acreedores. Era absolutamente imposible pagar, ni siquiera una cantidad a cuenta por pequeña que fuese, pues los interventores habían cerrado en absoluto la caja. Parece que esta medida era debida a que más que una suspensión de pagos la cosa presentaba el aspecto de una quiebra de algunos millones de pesetas ${ }^{60}$.

Verdaguer, sin embargo, continuará con la traducción:

A mi derecha se halla el Zauber Berg amenazante, con sus altas cumbres en las cuales ya me hallo como atrevido alpinista, pero sintiendo el vértigo del descenso que me espera. Es realmente algo apocalíptico. Espero que este verano habré conseguido llegar a la llanura. No puedes imaginarte las dificultades del librito, cuajado de filosofías, anatomía, fisiología, medicina, y literatura. Sus personajes son ya íntimos amigos míos y si no fuese por la íntima simpatía que siento hacia el doctor Behrens y porque me he enamorado de la señora Chauchat, no podría permanecer por más tiempo en ese sanatorio de Davos, en el cual pasan realmente cosas extraordinarias. He pasado y pasaré todavía muchas horas delante de la máquina de escribir y a pesar de que deseo haber ya terminado la tortura del desciframiento, cuando Hans Castorp y Joachim hayan desaparecido sentiré una verdadera añoranza. El Zauber Berg fue quemado por los nazis en enormes cantidades ante la Universidad de Berlín, eso hace que para mí el libro sea más querido y sienta el placer al pensar que aparecerá en la maravillosa lengua latina de un pueblo civilizado. Para descansar de la Montaña tengo a mi izquierda el Dante vivo de Papini, que también estoy traduciendo para la Apolo y que he de entregar a fines de este mes. El enrevesado italiano de Papini me parece la cosa más fácil del mundo, cuando salgo del laberinto mágico de Mann ${ }^{61}$.

A través de su epistolario sabemos que Oliver Brachfeld le propuso publicar un capítulo en la revista Europa, que no consiguió sin embargo el permiso del editor ${ }^{62}$. Pese a los pronósticos de Verdaguer, el proyecto editorial de Apolo continuó resistiendo, si bien resulta muy ilustrativa la opinión que

${ }^{60}$ Cf. CMV , Cartes a la seva família (1903-1962), «Cartes al seu germà Joaquim» (44-117), 17 de julio de 1932, Ms. 3138, n. ${ }^{\circ}$ 103. Barcelona: Biblioteca de Catalunya.

${ }^{61}$ Cf. CMV, Cartes a la seva família (1903-1962), «Cartes al seu germà Joaquim» (44-117), 18 de mayo de 1933, Ms. 3138, n. ${ }^{\circ}$ 108. Barcelona: Biblioteca de Catalunya.

${ }^{62}$ Cf. CMV, Cartes a la seva família (1903-1962), «Cartes al seu germà Joaquim» (44-117), 26 de julio de 1933, Ms. 3138, n. ${ }^{\circ} 110$. Barcelona: Biblioteca de Catalunya. 
tenía el escritor menorquín con respecto a la situación de la editorial y, por extensión, del mundo editorial barcelonés:

La situación es realmente desesperada, a pesar de la sonrisa plácida y prometedora de grandes cosas del señor Monturiol. Me parece que si encontrase el submarino que inventó su famoso abuelo lo utilizaría inmediatamente. Se halla en una situación parecida a la mía en La Vanguardia, con la diferencia ;loado sea el Señor! de que a mí me presentan cuartillas y a él facturas. El pobre Apolo debe desear ardientemente otra hoja de parra para poderse tapar su faz (...) Lo lamentable del caso es que la mayoría de las editoriales de Barcelona se hallan por el estilo, incluso la potente y repugnante Casa Maucci63.

Finalmente, en su faceta de traductor también cabe destacar su trabajo en la editorial Iberia de Barcelona, donde publicará la traducción de La dama del antifaz (1929), de Prosper Mérimée, y Tempestades de acero (1930), de Ernst Jünger. Sabemos también que Verdaguer debía preparar las notas y dos estudios para el Estebanillo González y La Lozana andaluza, pero no tenemos noticia de su publicación ${ }^{64}$. En Iberia, Verdaguer también dará a conocer Rasputín, el dominador de mujeres (1929).

\section{CONCLUSIÓN}

Los proyectos editoriales de Mario Verdaguer coinciden en el tiempo con la etapa de mayor trascendencia de su obra de creación: seis novelas (La casa de las pulgas, 1925, La isla de oro, 1926; El marido, la mujer y la sombra, 1927; Piedras y viento, 1927; La mujer de los cuatro fantasmas, 1931, y Un intelectual y su carcoma, 1934); un libro de cuentos (Tres pipas, 1929); una obra teatral (El sonido teatral, 1930); dos biografías noveladas (Rasputín, 1930, y Las mujeres de la Revolución, 1932) y un libro de misceláneas bajo el seudónimo de T.S.H. Thompson (El enigma del despertar de China, 1931). En este lapso de tiempo —-desde 1924, cuando Balagué le ofrece la dirección de «La Novela Mensual», hasta 1939—, también tradujo diez novelas; escribió otras, por ahora ilocalizables, y fue el autor de cuatro obras de teatro, no representadas, y dos guiones de cine que no llegaron a filmarse ${ }^{65}$. Sin duda, el prosista literario que era Verdaguer debió entrever en sus incursiones editoriales - bien en su papel de traductor, editor de una revista como Mundo Ibérico o director literario de Apolo, e incluso Lux - una plataforma de difusión y un lugar donde podía conjugar proyectos editoriales nítidamente diferen-

${ }^{63}$ Cf. CMV , Cartes a la seva família (1903-1962), «Cartes al seu germà Joaquim» (44-117), 18 de febrero de 1935, Ms. 3138, n. ${ }^{\circ}$ 111. Barcelona: Biblioteca de Catalunya.

${ }^{64}$ Cf. CMV, Cartes a la seva família (1903-1962), «Cartes al seu germà Joaquim» (44-117), 22 de abril de 1932, Ms. 3138. Barcelona: Biblioteca de Catalunya.

${ }^{65}$ Tomo los datos de López Antuñano (1992: 12). 
ciados. No obstante, los intereses comerciales de los sellos y colecciones a los que estaba vinculado y las estrategias (no necesariamente literarias) encaminadas a su beneficio personal como autor no contribuyeron a promocionar ni los frutos de la generación del Arte Nuevo, ni las grandes obras del patrimonio literario español. La tensión irresoluta entre los intereses económicos y la proyección pública de Verdaguer, de un lado, y la exigencia literaria que ambicionó para sus actividades editoriales, de otro, no permitió que una revista como Mundo Ibérico (el ejemplo más claro de la encrucijada en la que se encontraba como autor, editor y crítico) apostara por una literatura más arriesgada. Tampoco pudo hacerlo en el catálogo de Lux: ni desde «La Novela Mensual», cuyo repertorio consistía en títulos populares de dudosa altura literaria, ni desde la serie «Grandes éxitos literarios», que pese a no ser una atalaya de la modernidad, sí le permitió publicar traducciones de Istrati, autor en la época en los altares, y dos de sus propias novelas — La isla de oro y la experimental El marido, la mujer y la sombra. Mayor alcance tuvo - al menos desde el punto de vista literario- su participación en la editorial Apolo, donde, no cabe olvidarlo, aparecieron sus traducciones de Papini, Zweig, Teixeira de Pascoaes, Alfred de Vigny o Thomas Mann. En esta editorial, acarició el difícil equilibrio entre la viabilidad comercial y el reconocimiento literario, y pudo asumir el compromiso de divulgar las nuevas letras europeas, centrando sobre todo su atención en la literatura alemana y la novela intelectual.

Los proyectos editoriales de Verdaguer y su tarea de traductor y director literario ejemplifican, en definitiva, la diversidad de funciones que las colecciones de su época desempeñaron en relación a los polos de compromiso y legitimidad (Sapiro, 2007: 10) ${ }^{66}$. En efecto, cuando se trata de obras de tipo comercial y destinadas al mercado editorial de gran consumo, Verdaguer no explicita su identidad o incluso la disfraza, como ocurre con asiduidad en el caso de «La Novela Mensual». En cambio, cuando el autor traducido ha sido ya legitimado por las instituciones — academias, premios, colecciones o revistas con capacidad para la consagración- el escritor menorquín descubre su identidad para favorecer asimismo su propio ascenso, no solo en el sistema literario nacional sino también en otros campos como el alemán. Así se pone de manifiesto en la firma de contrato con la casa Zlosnay, que se propone traducir todas sus obras, y le permite acceder a órganos de prensa como el Arbeiter Zeitung o a otros espacios como el húngaro o el checo, más familiarizados con el alemán que con el castellano ${ }^{67}$. Verdaguer también reconoce la

\footnotetext{
${ }^{66}$ Entendemos el término de compromiso en el sentido de compromiso social, moral, o estético. La legitimidad, por el contrario, es otorgada por las instituciones, que propician la institucionalización de una obra o de un autor. La traducción española del trabajo de Sapiro puede consultarse en Sanz Roig (2013, en prensa).

${ }^{67}$ Joaquín Verdaguer será también traducido al alemán como recuerda su hermano Mario: «Herr Joachim es todo lo contrario de Don Xim. Es un escritor europeo, cuya literatura es
} 
autoría en el caso de las traducciones de Papini, escritor consagrado en otros campos literarios como el francés, donde incluso había impulsado en esa lengua la revista La vrai Italie. O también en el caso de Zweig, traducido en la colección «Le Cabinet Cosmopolite», dirigida por un crítico tan destacado como Edmond Jaloux; Istrati, que en 1923 había publicado Kyra-Kyralina en la revista Europe de Romain Rolland, y se había consagrado en las páginas de La Nouvelle Revue Française, o Thomas Mann, cuya obra y personalidad habían adquirido reconocimiento por otros cauces ${ }^{68}$.

La figura contradictoria de Verdaguer, la heterogénea Mundo Ibérico - que ejemplifica bien la diferencia entre el proyecto editorial que imaginó Verdaguer y la publicación que finalmente llevó a cabo-, y las colecciones de la propia editorial Lux, que sacó a la luz experimentos vanguardistas, traducciones de encumbrados autores europeos y libros de escaso interés literario, encajan a la perfección con la imagen de aquellos autores que desde un punto de vista estético o ideológico se insertaron en un equilibrio incierto entre el academicismo y la modernidad. Arraigado en la tradición, bien instalada en su ánimo a través de los lazos familiares (el gran poeta catalán, Jacint Verdaguer, era primo de su padre), Mario Verdaguer no dejó de inclinarse hacia la novedad y las culturas de distinta procedencia, pero sucumbió también, ya por interés o por necesidad, a la novela popular y de consumo y a la mercantilización de la literatura en general. Ángel Dotor, crítico y periodista de las revistas La Esfera y El Nuevo Mundo, en las que también colaboraba Verdaguer, se refería precisamente a esta mercantilización de la literatura en un artículo de Mundo Ibérico:

Dentro de la producción literaria española (...) abunda notablemente el libro de nulo valor artístico y educativo, y hasta el que, peor que anodino, resulta perjudicial, morboso, por su latente virus salaz. Notoria es la enorme cantidad de obras eróticas, pornográficas habidas en los últimos años; literatura halagadora de atávicos instintos y pasiones subalternas, con la que los escritorzuelos desaprensivos y de baja estofa han venido inficionando el mercado y perjudicando, por ende, la

popular en Alemania, Holanda, Dinamarca, Países Escandinavos. Me decía muy sorprendido un escritor castellano amigo, después de un viaje por Alemania: «He visto el nombre de su hermano en lugar preferente, en los escaparates de todas las librerías de Alemania». [...] Por su parte, un periodista mallorquín [...] ha manifestado recientemente en la prensa, que los únicos libros de escritores españoles que había visto en los escaparates, eran las obras de Ortega y Gasset y de Joaquín Verdaguer. [...] Sus editores: Heimeran, de Munich, y Gothia de Estocolmo, van a lanzar ahora dos de sus obras todavía inéditas: Ich bin ein Jungeselle (Yo soy un solterón) y Das Spazieren gehen (El paseo) al mismo tiempo que la séptima edición de Die Kunst, Pfeife zu rauche que seguramente aumentarán la popularidad». Cf. «Mario y Joaquín Verdaguer vistos el uno por el otro» (1964: 14-16).

${ }^{68}$ Nos referimos, por un lado, a la notoriedad que le otorgaba su oposición al régimen nazi, y su participación en la «Commission des Arts et des Lettres» del Institut Internationale de Coopération Intellectuelle, y, por otro, al nuevo concepto del individuo que desde un punto de vista literario se desprendía de sus novelas. 
obra artística de mérito. Aparte de esa que podríamos llamar vergonzosa mercantilización de la literatura, suele manifestarse la carencia de ética profesional de parte de los escritores españoles ${ }^{69}$.

A este respecto, la osadía del escritor menorquín tal vez consistió en conciliar la tradición cultural y las opiniones de críticos orgánicos, con las obras de consumo y algunas de las magias de la nueva literatura de su época.

\section{BIBLIOGRAFÍA CITADA}

Arévalo, Just (2000). «Notes sobre editors, col·leccions i obres populars i de consum que sí varen existir a la Barcelona del primer terç de segle», Els Marges, 67 (octubre), pp. 107-123.

Aubert, Paul y Jean-Michel Desvois (2006). «Libros y medios de comunicación de masas», en Serge Salaün y Carlos Serrano (coords.), Los felices veinte. España, crisis y modernidad. Madrid: Marcial Pons, pp. 55-91. [Temps de crise et «années folles». Les années 20 en Espagne (1917-1930). Essai d'histoire culturelle. París: Presses de l'Université de Paris-Sorbonne, 2002, pp. 41-70].

Bitzoc. «Mario Verdaguer. Obra inédita» (número monográfico), 1992, 14-15 (noviembre), pp. 2-252.

Bourdieu, Pierre (1977). «La production de la croyance: contribution à une economie des biens symbolics», Actes de la Recherche en Sciences Sociales, 13, pp. 3-43.

Bourdieu, Pierre (1999). «Une révolution conservatrice dans l'édition», Actes de la Recherche en Sciences Sociales, 126/127, pp. 3-28.

Cansinos Assens, Rafael (1927). «Mario Verdaguer», en La nueva literatura. IV. La evolución de la novela (1917-1927). Madrid: Páez, pp. 458-478.

Espagne, Michel (2009). «Transferts culturels et histoire du livre», en Histoire et civilisation du livre. 5, pp. 201-218.

Díaz-Plaja, Guillermo (1966). Memoria de una generación destruida (1930-1936). Barcelona: Delos-Aymà.

Fuentes Mollá, Rafael (1985). La novela vanguardista de Mario Verdaguer. Barcelona: Diputación de Barcelona.

Gasch, Sebastià (1971). «El arte de vanguardia en Barcelona», en Cuadernos Hispanoamericanos, 253-254 (enero-febrero), p. 142.

Gracia, Jordi (2000). «Un experimento prematuro: la revista Mundo Ibérico (1927)», en Ínsula, 646 (octubre), pp. 24-25.

Gracia, Jordi (2000). «La conciencia astillada del escritor Mario Verdaguer», en Francis Lough (ed.), Hacia la nueva novela. Essays on the Spanish Avant-Garde Novel. Oxford/ Berna: Peter Lang.

Ibarz, Virgilio y Manuel Villegas (2002). «Ferenc Olivér Brachfeld (1908-1967): Un psicólogo húngaro en Barcelona», en Revista de Historia de la Psicologí. 3-4. Vol. 23, pp. 265-275.

Lafarga, Francisco y Luis Pegenaute (2009). Diccionario Histórico de la Traducción en España. Madrid: Gredos.

La Gaceta Literaria (1980). Vaduz/ Liechenstein: Topos Verlag AG.

López Antuñano, José Gabriel (1992). «Màrius Verdaguer en su laberinto», en Bitzoc, 1415 (noviembre), pp. 2-28.

\footnotetext{
${ }^{69}$ Ángel Dotor, «Notas acerca del libro y el idioma», Mundo Ibérico, 5 de junio de 1927 n. ${ }^{\circ} 1$, pp. $17-18$.
} 
López Antuñano, José Gabriel (1994). Mario Verdaguer, un escritor proteico. Madrid: Pliegos. Llanas, Manuel (2005). L'edició a Catalunya: el segle XX (fins a 1939). Barcelona: Gremi d'Editors de Catalunya.

Llanas, Manuel y Ramon Pinyol (2009). «L'activitat de Férenc Oliver Brachfeld a Catalunya: algunes notícies», en Actes del XIVè Col-loqui Internacional de Llengua i Literatura Catalanes (Budapest 2006). Barcelona: Publicacions de l'Abadia de Montserrat, pp. 295308.

Ràfols, José F (1951-1954). Diccionario biográfico de artistas de Cataluña: desde la época romana hasta nuestros días. 3 vols. Barcelona: Millá.

Ródenas, Domingo (ed.) (1997). Proceder a sabiendas. Antología de la narrativa de vanguardia española 1923-1936. Barcelona: Alba Editorial.

Ródenas, Domingo (2009). «El novelista Mario Verdaguer y su carcoma», en Travesías Vanguardistas: ensayos sobre la prosa del Arte Nuevo. Madrid: Devenir Ensayo, pp. 431491.

Palau i Dulcet, Antoni (1948-1977). Manual del librero hispanoamericano: bibliografía general española e hispanoamericana desde la invención de la imprenta hasta nuestros tiempos con el valor comercial de los impresos descritos. 28 vols. y 7 vols. de índices. Barcelona: Llibreria Palau [2 $2^{\mathrm{a}}$ edición revisada y corregida por el autor].

Sánchez Álvarez-Insúa, Alberto (1996). Bibliografía e historia de las colecciones literarias en España (1907-1957). Madrid: Libris.

Santonja, Gonzalo (1989). La República de los libros. El nuevo libro popular de la Segunda República. Madrid: Anthropos.

Sanz Roig, Diana (ed.) (2013, en prensa). Bourdieu después de Bourdieu. Madrid: Arco/ Libros.

Sanz Roig, Diana (2010). «Las colaboraciones de Mario Verdaguer en La Vanguardia», en Serge Salaün (ed.), Entre l'ancien et le nouveau. Le socle et la lézarde (Espagne XVIIIèXXè). Vol. 2. París: Centre de Recherche sur l'Espagne Contemporaine, Université de la Sorbonne Nouvelle, pp. 621-652.

Sanz Roig, Diana (2011). «La professionnalisation de la critique littéraire espagnole aux années de l'entre-deux-guerres», en Actes du IVème Congrès de l'Association Française de Sociologie «Création, innovation et changement intellectuels» (Grenoble, 5-8 de julio de 2011).

Sapiro, Gisèle (2007). «Pour une approche sociologique des relations entre littérature et idéologie», en Contextes. 2. http://contextes.revues.org/index165.html.

Verdaguer, Mario (2009). Medio siglo de vida intima barcelonesa. Palma de Mallorca: Guillermo Canals/ Ediciones UIB [Barcelona: Editorial Barna, 1957].

Verdaguer, Mario (1964). «Recuerdos vicenses», en Ausa, 50. Vol. 5, pp. 149-156.

Verdaguer, Mario y Joaquín Verdaguer (1964). «Mario y Joaquín Verdaguer visto el uno por el otro», en Revista de Menorca. Mahón: Taller Coll.

Verdaguer, Mario (1974). «Introducción» a Un intelectual y su carcoma, en Las mejores novelas contemporáneas. Barcelona: Planeta [ $6^{\mathrm{a}}$ ed.].

Verdaguer, Mario. Correspondència rebuda per Mario Verdaguer, Ms. 3138 y Ms. 3139. Barcelona: Biblioteca de Catalunya.

Fecha de recepción: 5 de agosto de 2010

Fecha de aceptación: 1 de marzo de 2011 